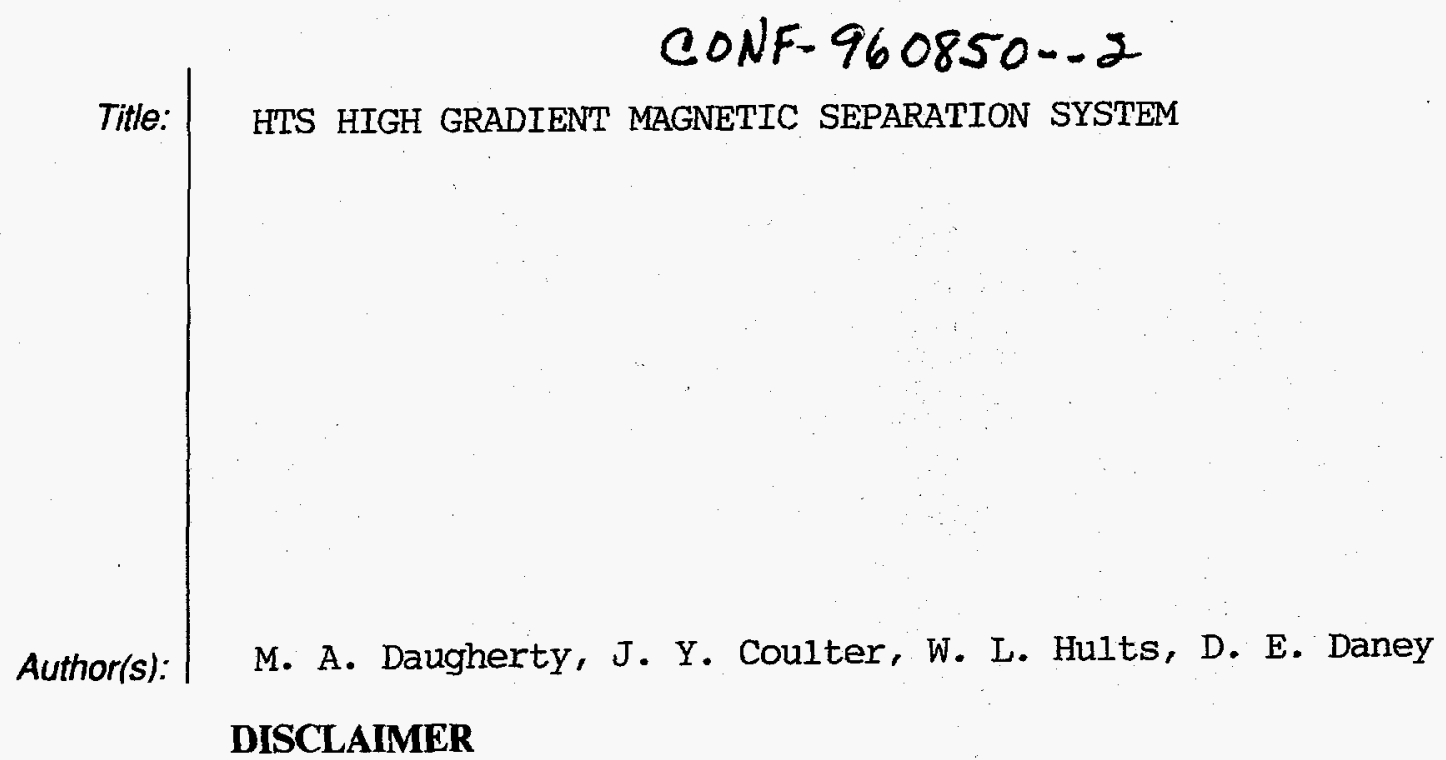

This report was prepared as an account of work sponsored by an agency of the United States Government. Neither the United States Government nor any agency thereof, nor any of their employees, makes any warranty, express or implied, or assumes any legal liability or responsibility for the accuracy, completeness, or usefulness of any information, apparatus, product, or process disclosed, or represents that its use would not infringe privately owned rights. Reference herein to any specific commercial product, process, or service by trade name, trademark, manufacturer, or otherwise does not necessarily constitute or imply its endorsement, recommendation, or favoring by the United States Government or any agency thereof. The views and opinions of authors expressed herein do not necessarily state or reflect those of the United States Government or any agency thereof.

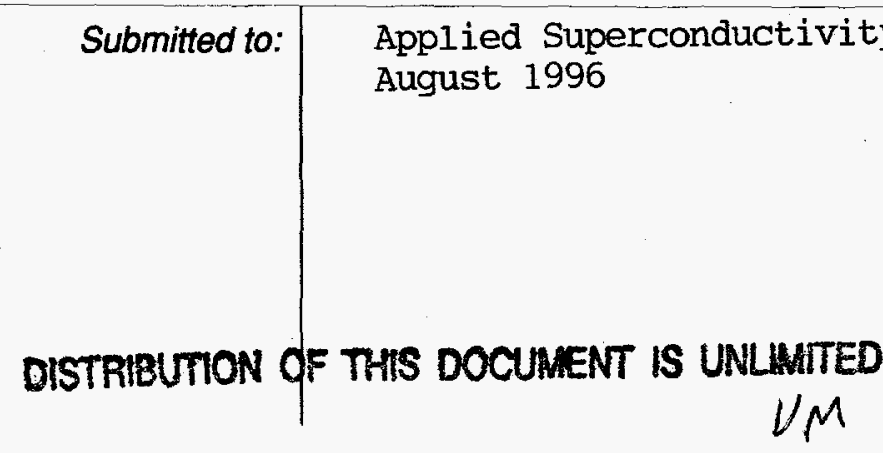
Applied Superconductivity Conf., Pittsburgh, PA
August 1996

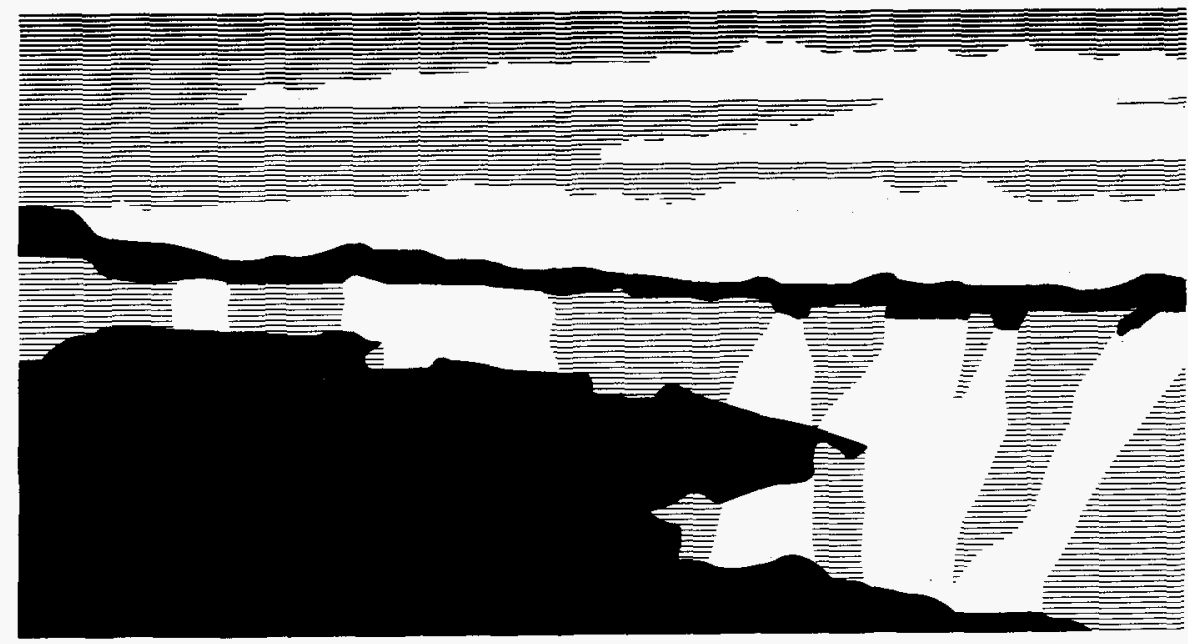

Los Alamos National Laboratory, an affirmative action/equal opportunity employer, is operated by the University of California for the U.S. Department of Energy under contract W-7405-ENG-36. By acceptance of this article, the publisher recognizes that the U.S. Government retains a nonexclusive, royalty-free license to publish or reproduce the published form of this contribution, or to allow others to do so, for U.S. Government purposes. The Los Alamos National Laboratory requests that the publisher identify this article as work pertormed under the auspices of the U.S. Department of Energy. 
$=\ldots, \quad \because *$ 


\section{DISCLAIMER}

Portions of this document may be illegible in electronic image products. Images are produced from the best available original document. 



\section{DISCLAIMER}

This report was prepared as an account of work sponsored by an agency of the United States Government. Neither the United States Government nor any agency thereof, nor any of their employees, makes any warranty, express or implied, or assumes any legal liability or responsibility for the accuracy, completeness, or usefulness of any information, apparatus, product, or process disclosed, or represents that its use would not infringe privately owned rights. Reference herein to any specific commercial product, process, or service by trade name, trademark, manufacturer, or otherwise does not necessarily constitute or imply its endorsement, recommendation, or favoring by the United States Government or any agency thereof. The views and opinions of authors expressed herein do not necessarily state or reflect those of the United States Government or any agency thereof. 



\title{
HTS High Gradient Magnetic Separation System
}

\author{
M. A. Daugherty, J. Y. Coulter, W. L. Hults, D. E. Daney, D. D. Hill, D. E. McMurry, \\ M. C. Martinez. L. G. Phillips, J. O. Willis, H. J. Boenig and F. C. Prenger \\ Les Alamos National Laboratory, Los Alamos, NM \\ A. J. Rodenbush and S. Young \\ American Superconductor Corp., Westborough, MA
}

\begin{abstract}
We report on the assembly, characterization and operation of a high temperature superconducting (HTS) magnetic separator. The magnet is made of $624 \mathrm{~m}$ of Silver/BSCCO superconducting wire and has overall dimensions of $18 \mathrm{~cm} O D, 15.5 \mathrm{~cm}$ height and $5 \mathrm{~cm}$ ID. The HTS current leads are designed to operate with the warm end at $75 \mathrm{~K}$ and the cold end at $27 \mathrm{~K}$. The system operates in a vacuum and is cooled by a two stage Gifford-McMahon cryocooler. The upper stage of the cryocooler cools the thermal shield and two heat pipe thermal intercepts. The lower stage of the cryocooler cools the HTS magnet and the bottom end of the HTS current leads. The HTS magnet was initially characterized in liquid cryogens. We report on the current-voltage (I-V) characteristics of the HTS magnet at temperatures ranging from 15 to $45 \mathrm{~K}$. At $40 \mathrm{~K}$ the magnet can generate a central field of $2.0 \mathrm{~T}$ at a current of 120 A.
\end{abstract}

\section{INTRODUCTION}

High Gradient Magnetic Separation (HGMS) is a powerful technique which can be used to separate widely dispersed contaminants from a host material. This technology can separate magnetic solids from other solids, liquids or gases. As the name implies HGMS uses large magnetic field gradients to separate ferromagnetic and paramagnetic particles. HGMS separators usually consist of a high-field solenoid magnet, the bore of which contains a fine-structured, ferromagnetic matrix material. The matrix material locally distorts the magnetic field and creates large field gradients in the vicinity of the matrix elements. These elements then become trapping sites for magnetic particles and are the basis for the magnetic separation.

Magnetic separation using low-field permanent magnets or electromagnets has been used in certain processing industries for several decades to separate ferromagnetic materials. These materials magnetically saturate at low fields and are easily magnetized. However, ferromagnetism is relatively rare, being confined to compounds of iron, nickel and cobalt, and certain rare earth elements.

Manuscript received August 26, 1996.

This research was supported by the Department of Energy, Office of Energy Efficiency and Renewable Energy.
Paramagnetism, on the other hand, is very common with 55 elements having paramagnetic properties. In a sufficiently strong applied field, paramagnetic materials may be more highly magnetized than some ferromagnetic materials. With the use of superconducting magnets, the required high-gradient magnetic fields are now possible. Several low temperature superconducting magnetic separation systems are now in operation [1], [2].

In this paper we discuss the assembly, characterization and operation of a prototype high temperature superconducting (HTS) HGMS magnet system. The magnet and HTS portions of the current leads were made by American Superconductor Corporation. The magnet is conductively cooled and operates in a vacuum. The conductor is silver/Bi2223 HTS tape [3].

\section{APPARATUS}

\section{A. Design}

The design of the magnet system is discussed in detail in an earlier paper [4]. The design thermal loads on the system are summarized in Table $I$. The system is shown schematically in Fig. 1. The HTS magnet, current leads and thermal shield are supported by G-10 tubes and hung from the lid of the vacuum vessel. The cryocooler is mounted on the vessel lid and connected to the thermal shield top plate and the magnet cooling plate with flexible links to provide vibration isolation. The upper stage of the cryocooler cools the thermal shield and the heat pipe thermal intercepts. The heat pipe thermal intercepts combine high thermal conductivity with good electrical insulation and ensure that the upper end of the HTS portion of the current leads is adequately cooled [5], [6].

The lower stage of the cryocooler cools the HTS magnet and the bottom of the HTS current leads. The bottom of the leads are connected to the cooling plate by copper braid. The magnet is bolted to the cooling plate. The bottom plate of the HTS magnet and the magnet bore tube are made of copper and provide the conductive path into the windings for cooling. The magnet consists of individual double pancake windings which are stacked on the copper bore tube. There is a protective $\mathrm{G}-10$ housing covering the windings. Current lead mounting pads are provided to bolt the current leads to the magnet. The specifications for the magnet are shown in Table II. 
TABLE I

Design Steady State Heat loads

$80 \mathrm{~K}$ STAGE

Radiation

Supports (Conduction)

Current leads

(100 A nominal design)

Total

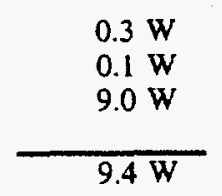

$20 \mathrm{~K}$ STAGE

Radiation

Magnet generation

Supports(conduction)

Current leads

Total
TABLE II

His Magnet Spectications
Conductor Type

Number of Tums

Conductor Length

Number of Double Pancake Coils

Magnet Outer Diameter

Magnet Height

Magnet Inner Bore Diameter

Warm Bore Diameter

Specified Operating Temperature

Specified Magnetic Field

Specified Power Dissipation
$\mathrm{Bi}-2223$

1,830

$624 \mathrm{~m}$

17

$18 \mathrm{~cm}$

$15.5 \mathrm{~cm}$

$5 \mathrm{~cm}$

$2.5 \mathrm{~cm}$

$27 \mathrm{~K}$

$1 \mathrm{~T}$

$0.2 \mathrm{~W}$

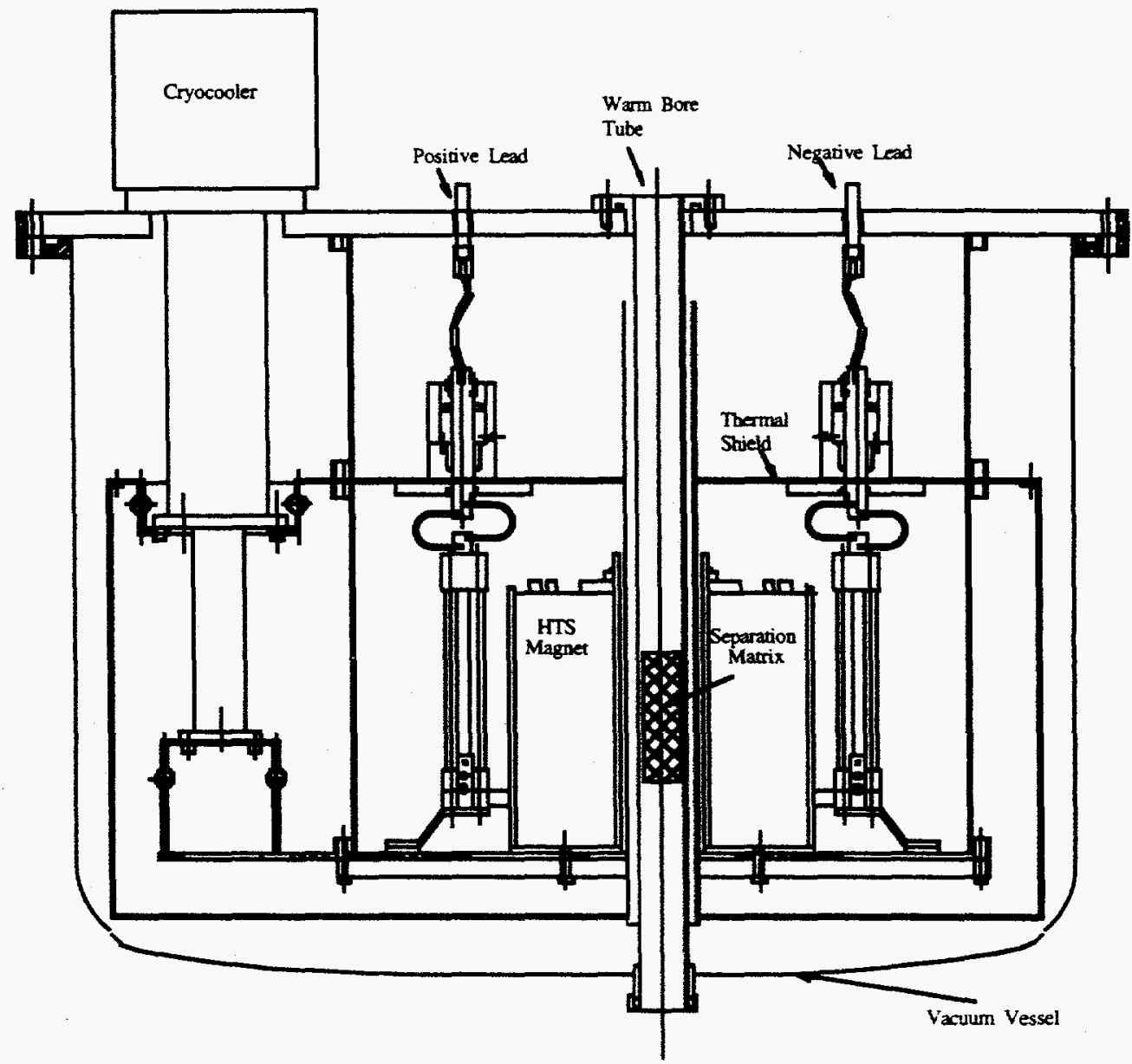

Fig. 1 Schematic of the HTS high gradient magnetic separation system 


\section{B. Assembly}

Indium foil was used to improve the thermal conductivity of the connections to the cryocooler, magnet, heat pipe thermal intercepts, and the current leads. The foil was also used in the bolted electrical connections between the magnet and the current leads. Care was taken when bolting the current leads to the magnet to ensure that good electrical contact was made and simultaneously ensure that the leads were properly supported. Multilayer insulation (MLI) blankets were used to reduce radiation heat transfer. Blankets with 32 layers were used on the thermal shield and 15 layers were used around the magnet and the cold plate. A heater was installed around the bottom of the flexible link at the lower stage of the cryocooler so the magnet temperature could be varied.

\section{Instrumentation}

Temperatures at the upper stage of the cryocooler, the thermal shield, the heat pipe thermal intercepts and the upper end of the HTS portion of the current leads were measured with Type $E$ thermocouples, a platinum resistance thermometer and cryogenic linear temperature sensors. The platinum resistance thermometer also provided a junction compensation temperature for the thermocouples. Temperatures at the lower stage of the cryocooler, the magnet cooling plate, and the lower end of the HTS portion of the current leads were measured with carbon glass thermometers and cryogenic linear temperature sensors. The magnet temperature was measured with three silicon diodes. The reported value of the magnet temperature is the average of that obtained from the three diodes.

Voltages were measured across the HTS portions of the current leads and across the magnet. The reported values for magnet voltage drop include the drop across the bolted connection between the current leads and the magnet. A computer controlled data acquisition system was used to monitor the magnet system and acquire the data.

\section{TEST PROCEDURE}

At the beginning of a run the heater was adjusted to the desired starting temperature for the magnet. When the temperature of the magnet was stable the current was ramped up to the desired value. During the ramp the voltage drop across the current leads and the magnet were monitored. When the desired current was obtained the ramp was stopped and the voltage across the magnet was monitored to determine when the inductive voltage drop in the magnet had sufficiently dissipated. This typically required about five minutes. The steady state magnet voltages were then recorded. All temperatures and voltages were monitored, displayed and recorded continuously during all runs.

\section{RESULTS}

The first run was made to verify that the HTS magnet could meet specifications when operating in a conductively cooled mode. The magnet specifications and physical description are summarized in Table II. The magnet was ramped to $1 \mathrm{~T}$ and the temperature was slowly increased from 12 to $29 \mathrm{~K}$ by using the heater on the lower flexible link. The results are shown in Fig. 2 as the data set labeled "Conduction Cooled." At $27 \mathrm{~K}$ and $1 \mathrm{~T}$ the magnet dissipation is approximately one half of the specified value of $200 \mathrm{~mW}$.

Earlier data obtained with the magnet immersed in liquid helium and neon are also shown in Fig. 2 for comparison. Losses are higher in the conduction cocled mode than in the liquid cryogens. One possible explanation is that local heating at joints and other locations in the magnet is not removed as efficiently in the conduction cooled mode. This can result in slight temperature gradients within the magnet which would cause locally higher dissipation.

Next a series of constant temperature runs were made at varying magnetic fields. The voltage drop across the magnet was measured at temperatures of $15,22,35,40$ and $45 \mathrm{~K}$. The results are shown in Fig. 3. As expected the voltage drop increases with increasing temperature and magnetic field. A field of $2 \mathrm{~T}$ was achieved at a temperature of $40 \mathrm{~K}$. At a temperature of $45 \mathrm{~K}$ a field of $1.66 \mathrm{~T}$ was obtained. The magnet was stable at all data points plotted in Fig. 3.

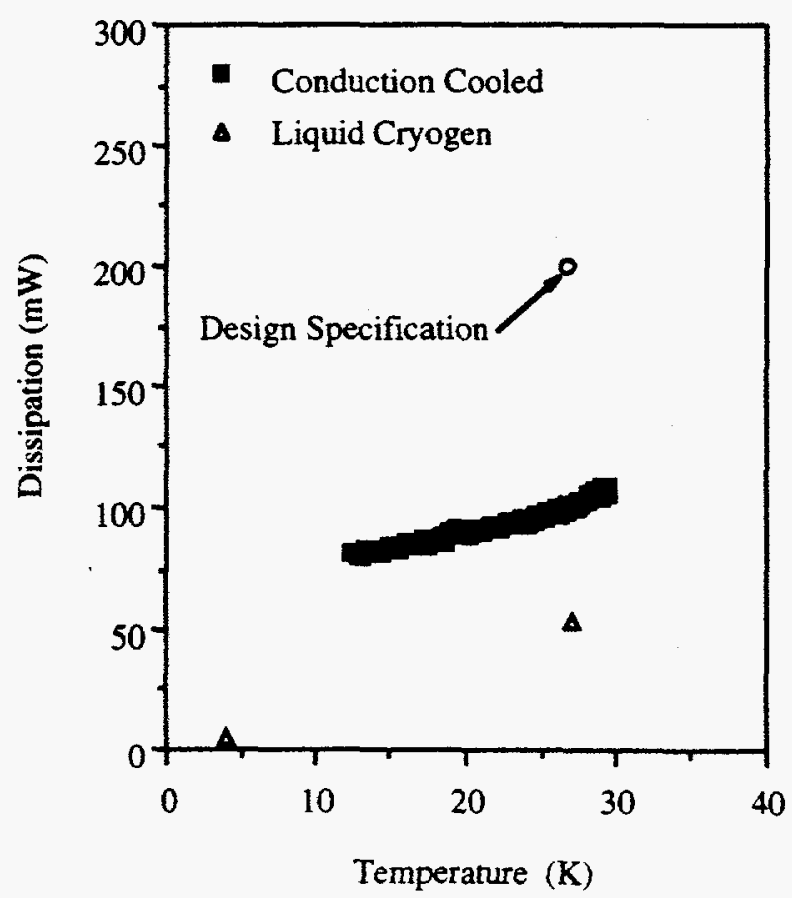

Fig. 2 Magnet dissipation as a function of temperature at a constant field of $1 \mathrm{~T}$. 


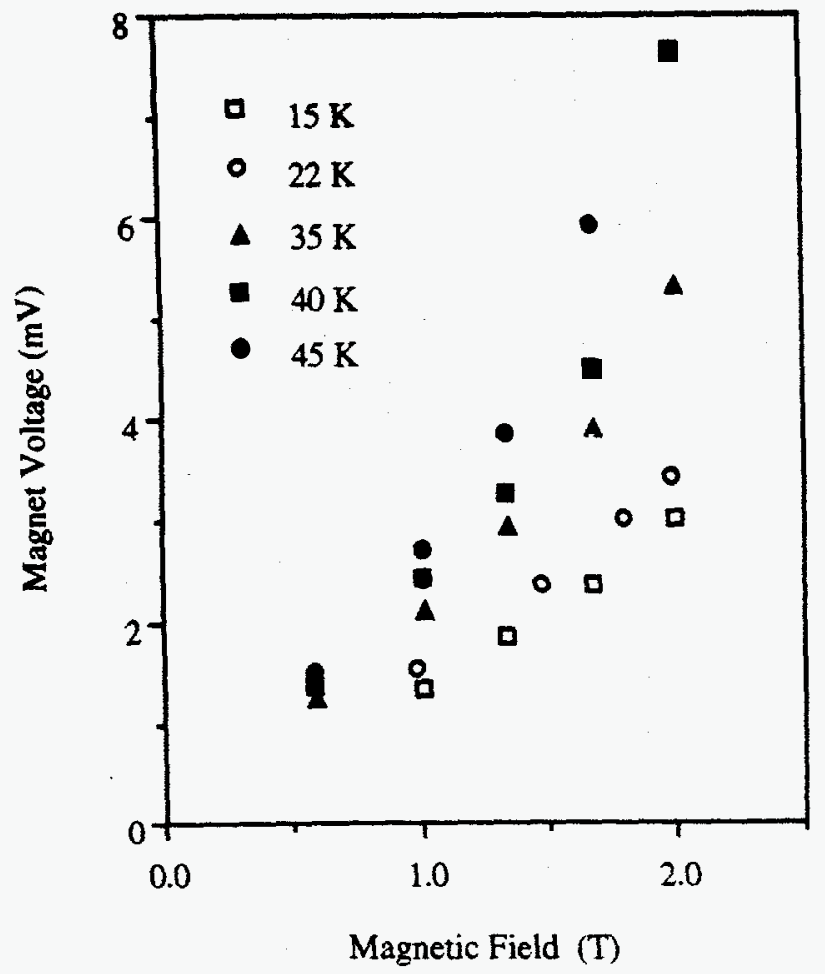

Fig. 3 Voltage drop across the magnet at fields ranging from 0.5 to $2.0 \mathrm{~T}$ and temperatures ranging from 15 to $45 \mathrm{~K}$.

\section{CONCLUSIONS}

The total length of the conductor in the magnet is $624 \mathrm{~m}$. If the $1 \mu \mathrm{V} / \mathrm{cm}$ criteria is applied to this length a voltage of $62.4 \mathrm{mV}$ is obtained. At $2 \mathrm{~T}$ and $40 \mathrm{~K}$ the magnet voltage drop is a factor of 8 smaller than this value.
The magnet has exceeded its performance requirements by a factor of 2 in magnetic field and a factor of 1.6 in temperature. Commercial magnetic separation systems operate at a field of approximately $2 \mathrm{~T}$. This system has demonstrated the ability of HTS magnets to provide this magnetic field in a reliable manner. The magnet is now qualified to serve as a test bed for industrial HGMS processes.

\section{ACKNOWLEDGMENT}

The authors gratefully acknowledge the technical assistance of Marcell Buford, Claude Conner, Steven Limback, J. Randy Groves, Timothy Pierce and Roy Rockage.

\section{REFERENCES}

[1] J. A. Selvaggi, P. Vander Arend and J. Colwell, "An industrial superconducting high gradient magnetic separator," Advances in Cryogenic Engineering, Vol. 33, pp. 53-60, 1988.

[2] J. A. Selvaggi, T. Kranyecz and S. Bell, "A 124" warm bore superconducting ironclad high gradient magnetic separator," Applied Superconductivity, Vol. 1, No. 1/2, pp. 13-18, 1993.

[3] W.L. Carter, G.N. Riley Jr, A. Otto, D.R. Parker, C.J. Christopherson, L.J. Masur, and D. Buczek, "Adyances in the Development of Silver Sheathed $(\mathrm{Bi}, \mathrm{Pb}) 2223$ Composite Conductors," IEEE Trans. on Appl. Superconductivity, Vol. 5. pp. 1145-1149, 1995.

[4] M. Daugherty, F. Prenger, D. Hill, D. Daney, L. Worl, A. Schake and D. Padilla, "Application of High-Temperature Superconductors to High-Gradient Magnetic Separation," 29th Intersociety Energy Conversion Engineering Conference. Monterey, CA, August 7.11. pp. 1502-1507, 1994

[5] M.A. Daugherty, D.E. Daney, F.C. Prenger, D.D. Hill, P.M. Williams and H.J. Boenig. "Assembly and Testing of a Composite Heat Pipe Thermal Intercept for HTS Current Leads," in press, Advances in Cryogenic Engineering, Vol. 41 .

[6] M.A. Daugherty, F.C. Prenger, D.D. Hill, D.E. Daney and K.A. Woloshun. "HTS Current Lead Using a Composite Heat Pipe," IEEE Transactions on Applied Superconductivity, Vol. 5, No. 2, pp. 773-776, 1995 . 